\title{
Oral versus Intravenous Paracetamol for Perioperative Analgesia in Patients Undergoing Total Abdominal Hysterectomy - A Randomised Double-Blind Controlled Trial
}

\author{
Archana Khokar ${ }^{1}$, Medha Mohtaㄹ, Himanshu Bhasin² ${ }^{3}$ Swaraj Jyoti Sonowal ${ }^{4}$ \\ ${ }^{1,3}$ Department of Anaesthesiology, Atal Bihari Vajpayee Institute of Medical Sciences \& Dr Ram \\ Manohar Lohia Hospital, New Delhi, India. ${ }^{2}$ Department of Anaesthesiology, University College \\ of Medical Sciences \& Guru Teg Bahadur Hospital, New Delhi, India. ${ }^{4}$ Department of \\ Anaesthesiology, Dr Bhubaneswar Borooh Cancer Institute, Guwahati, Assam, India.
}

\section{ABSTRACT}

\section{BACKGROUND}

Paracetamol has been commonly used for perioperative pain management. The perceived benefits of IV paracetamol (PCM) over oral are few if oral PCM is given sometime before surgery. We wanted to compare the effects of oral and intravenous paracetamol on perioperative pain management in patients undergoing total abdominal hysterectomy under general anaesthesia.

\section{METHODS}

Sixty-four female patients of American Society of Anesthesiologists (ASA) I / II, in the age group of 18 - 70 years, weighing $40-80 \mathrm{Kg}$, undergoing total abdominal hysterectomy (TAH) were randomised using computer-generated random number table, into two groups. They received oral dispersible $1 \mathrm{~g}$ PCM tablets (group PO) at least 45 minutes prior to surgery or intravenous (IV) PCM $1 \mathrm{~g}$ (group PI) after induction of anaesthesia. VAS pain scores were recorded and rescue analgesia with tramadol was provided postoperatively.

\section{RESULTS}

The primary outcome measure, time to first rescue analgesic, was statistically similar in both groups. The secondary outcome measures i.e., pain scores, postoperative 24 hours tramadol requirements, patient satisfaction scores and complications were also comparable.

\section{CONCLUSIONS}

Considering the similar efficacy and side effect profile but a much lower cost of oral PCM, routine administration of oral PCM 45 minutes before induction of anaesthesia may be an acceptable alternative to routine intraoperative IV PCM infusion.
Corresponding Author: Dr. Archana Khokar, RZG-687, Rajnagar Part-2, Palam Colony - 77,

New Delhi, India.

E-mail: archukhokar89@gmail.com

DOI: $10.14260 /$ jemds/2021/117

How to Cite This Article:

Khokar A, Mohta M, Bhasin H, et al. Oral versus intravenous paracetamol for perioperative analgesia in patients undergoing total abdominal hysterectomy a randomised double-blind controlled trial. J Evolution Med Dent Sci 2021;10(08):541545, DOI: $10.14260 / \mathrm{jemds} / 2021 / 117$

Submission 15-10-2020,

Peer Review 26-12-2020,

Acceptance 26-06-2020,

Published 22-02-2021.

Copyright (c) 2021 Archana Khokar et al. This is an open access article distributed under Creative Commons Attribution License [Attribution 4.0 International (CC BY 4.0)]

\section{KEY WORDS}

Paracetamol, Intravenous, Oral, VAS Pain Score, Analgesia 


\section{BACKGROUND}

Paracetamol has been widely used for over a century as an effective analgesic and antipyretic agent with an established efficacy and tolerability. ${ }^{1-4,5}$ It is currently the most commonly used drug for the treatment of postoperative pain as monotherapy or as a part of multimodal therapy. ${ }^{6}$ The consumption of opioids, other analgesics and their related side effects have been shown to be reduced with the use of PCM.7,8,9 Paracetamol has the advantage of being available in oral, intravenous and rectal formulations.

Intravenous PCM has been very commonly used in perioperative period for providing pain relief due to its multiple advantages in terms of safety, efficacy, rapid onset of action, predictable pharmacokinetics and few clinically significant drug interactions.5,10,11,12 IV PCM in standard equivalent doses provides analgesia comparable with nonsteroidal anti-inflammatory drugs (NSAIDs) and tramadol with minimal side effects. ${ }^{10,13}$ However, IV preparations are significantly more expensive and their administration is also more complex. Oral PCM preparation is very cheap and its administration is also simple. It is completely absorbed from the proximal small intestine with a peak plasma concentration achieved in 30 to 60 minutes which is facilitated by the fasting status of the patient. The bioavailability of oral PCM is time, dose and age dependent. ${ }^{14,15}$

There is an evidence of efficacy of oral PCM for acute pain management and it has been suggested that its role in perioperative pain management needs to be further explored. ${ }^{16,17,18}$ To our knowledge, there has been no study comparing the intravenous and oral routes of paracetamol administration for perioperative pain relief in female patients undergoing total abdominal hysterectomy. Therefore, we conducted a randomised controlled trial to compare the analgesic efficacy of paracetamol via oral and intravenous routes in patients undergoing total abdominal hysterectomy under general anaesthesia (GA).

\section{METHODS}

The present randomised, double blind controlled trial was undertaken after approval from the institutional ethics committee-human research and obtaining written informed consent from each patient. The trial was prospectively registered at Clinical Trials Registry-India. The study was carried out in 64 ASA grade I / II patients, aged between 18 70 years, weighing $40-80 \mathrm{Kg}$ undergoing abdominal hysterectomy with Pfannenstiel incision under general anaesthesia. The study was conducted from November 2014 to April 2016 in the Department of Anaesthesiology \& Critical Care and the Department of Obstetrics \& Gynaecology, University College of Medical Sciences \& Guru Teg Bahar Hospital, Delhi. Patients with history of daily intake of analgesics, intake of any analgesic in preceding 24 hours of surgery, history of convulsive disorders, those on antiepileptic treatment, or having liver and kidney dysfunction were excluded. The patients were randomly allocated into two groups 'PI' and 'PO' using computer generated random number tables. A sealed envelope technique was used to maintain allocation concealment. To maintain blinding, double dummy technique was used. An anaesthesiologist not involved in the study prepared the drug with their placebo in a separate area. All patients received premedication in the form of tab alprazolam $0.25 \mathrm{mg}$ in the night and 2 hours before surgery. In the preoperative room, the patients were explained and instructed about the pain assessment using visual analogue scale (0 - 100; 0 - no pain, 100 - worst imaginable pain). According to group allocation, to group ' $\mathrm{PO}$ ', oral dispersible PCM $1 \mathrm{~g}$ tablets were given approximately $45 \mathrm{~min}$ before the induction of anaesthesia and $100 \mathrm{ml}$ of normal saline after induction of anaesthesia; whereas Group 'PI' patients received oral dispersible placebo tablet in the preoperative period and IV PCM $1 \mathrm{gm}$ after induction of anaesthesia. Drugs were given by the staff not involved in the study.

In operating room, standard monitoring in the form of continuous electrocardiogram (ECG), heart rate (HR), noninvasive blood pressure (NIBP) and pulse oximetry $\left(\mathrm{SpO}_{2}\right)$ was started. Baseline vitals were recorded. IV cannula was secured, and ringer lactate infusion started. Haemodynamics were monitored during intraoperative as well as post-operative period.

Standard anaesthetic technique for general anaesthesia was followed in all the patients. Anaesthesia was induced with inj. morphine $0.1 \mathrm{mg} / \mathrm{Kg}$ and inj. propofol $2 \mathrm{mg} / \mathrm{Kg}$ followed by inj. vecuronium $0.1 \mathrm{mg} / \mathrm{Kg}$ to facilitate orotracheal intubation. Anaesthesia was maintained with oxygen, nitrous oxide, isoflurane and top-up doses of vecuronium. At the end of surgery, infiltration of skin incision was carried out with $0.25 \%$ plain bupivacaine and ondansetron $4 \mathrm{mg}$ IV was given to all the patients. Neuromuscular blockade was reversed using neostigmine $0.05 \mathrm{mg} / \mathrm{Kg}$ and glycopyrrolate $0.01 \mathrm{mg} /$ Kg. The durations of surgery and anaesthesia were recorded.

Pain was assessed using VAS pain score on arrival in the post anaesthesia care unit (PACU), then every $30 \mathrm{~min}$ interval for initial 2 hours, then at 4, 8, 12 and 24 hours in the postoperative period. Rescue analgesia was provided with tramadol $1 \mathrm{mg} / \mathrm{Kg}$ by slow IV injection whenever VAS pain score was $>30 \mathrm{~mm}$. This time was noted as the time to first analgesic requirement. Same dose was repeated if pain relief was inadequate with the initial dose. In the ward, analgesia was provided with inj. tramadol $1 \mathrm{mg} / \mathrm{Kg}$ whenever VAS pain score was $>30 \mathrm{~mm}$. If pain relief was not adequate with tramadol $1 \mathrm{mg} / \mathrm{Kg}$, inj. diclofenac $75 \mathrm{mg}$ by slow IV infusion was given. Intravenous PCM $1 \mathrm{~g}$ was given if adequate pain relief could not be achieved even after giving diclofenac. The total analgesic requirement was calculated in terms of tramadol consumption, considering diclofenac $75 \mathrm{mg}$ and IV PCM 1 g equivalent to IV tramadol 100 mg. ${ }^{19,20}$ Any episode of nausea, vomiting or hypotension was managed and recorded. Patient's satisfaction with the pain relief was asked and graded as 'good', 'average' or 'poor'.

The primary outcome measure was time to first rescue analgesic; whereas, secondary outcome measures were pain scores, postoperative 24 hours analgesic requirements and patient satisfaction score.

\section{Sample Size}

Considering a standard deviation of $38 \mathrm{~min}$ for time to rescue analgesia in patients undergoing total abdominal hysterectomy under general anaesthesia, ${ }^{21} 29$ patients in each group were needed to detect a difference of $30 \mathrm{~min}$ in time to 
rescue analgesia with a power of $80 \%$ at $5 \%$ significance level. However, to compensate for any attrition in data, $10 \%$ of this number was added so as to give a final sample size of 32 patients in each group.

\section{Statistical Analysis}

Statistical analysis was performed using Statistical Package for SPSS version 20.0. Unpaired Student's t-test was used to compare mean age, weight, time to first rescue analgesic and postoperative 24 hours analgesic requirement. Repeated measures ANOVA was used to perform inter-group comparisons for VAS pain scores. Fisher's exact test or chisquare test was used to compare ASA grade, patient satisfaction score and complications. Post hoc analysis was done with Tukey's test. A value of $\mathrm{P}<0.05$ was considered statistically significant.

\section{RESULTS}

Demographic profile was comparable among both the groups as shown in Table 1.

\begin{tabular}{|cccc|}
\hline $\begin{array}{c}\text { Demographics and Patient } \\
\text { Characteristics }\end{array}$ & $\begin{array}{c}\text { Group PI } \\
(\mathbf{N}=\mathbf{3 2})\end{array}$ & $\begin{array}{c}\text { Group PO } \\
(\mathbf{N}=\mathbf{3 2})\end{array}$ & P-Value \\
\hline Age (years) & $42.4 \pm 6.0$ & $42.8 \pm 9.3$ & 0.823 \\
Weight (Kg) & $57.1 \pm 10.04$ & $53.69 \pm 10.07$ & 0.185 \\
ASA I / I & $23 / 9$ & $18 / 14$ & 0.297 \\
\hline $\begin{array}{c}\text { Duration of surgery } \\
\text { Duration of anaesthesia }\end{array}$ & $129.3 \pm 42.2$ & $135.1 \pm 43.7$ & 0.592 \\
$\begin{array}{c}\text { Time of tablet before induction } \\
\text { (min) }\end{array}$ & $54.7 \pm 7.5$ & $56.8 \pm 10.2$ & 0.341 \\
\hline $\begin{array}{c}\text { Time of infusion from induction } \\
\text { (min) }\end{array}$ & $16.6 \pm 9.7$ & $12.2 \pm 6.1$ & 0.032 \\
\hline Table 1. Demographic Profile and Other Patient Characteristics \\
\hline
\end{tabular}

In the present study, analgesic efficacy of oral and IV PCM was studied in terms of time to first analgesic requirement (TFR), 24 hours analgesic requirement and VAS pain scores.

\begin{tabular}{|cccc|}
\hline $\begin{array}{c}\text { Analgesic Requirement at } \\
\text { Various Time Points }\end{array}$ & $\begin{array}{c}\text { Group PI } \\
\text { (N = 32) }\end{array}$ & $\begin{array}{c}\text { Group PO } \\
\text { (N = 32) }\end{array}$ & P-Value \\
\hline $\begin{array}{c}\text { TFR induction (min) } \\
\text { TFR reversal (min) }\end{array}$ & $227.3 \pm 96.7$ & $215.5 \pm 87.0$ & 0.608 \\
$\begin{array}{c}\text { Total tramadol requirement in } \\
\text { 24 hours (m) }\end{array}$ & $230.4 \pm 91.2$ & $74.2 \pm 94.5$ & 0.792 \\
$\begin{array}{c}\text { Total analgesic requirement in } \\
\text { 24 hours (m) }\end{array}$ & 260 & $195.6 \pm 91.7$ & 0.094 \\
\hline Table 2. Time to First Rescue Analgesia and Analgesic Requirement \\
\hline
\end{tabular}

TFR was noted from the time of induction as well as reversal. There was no statistically significant difference in TFR from induction and reversal between the groups as shown in Table 2. In group 'PI', nine patients received inj. diclofenac and two patients received diclofenac and inj. PCM in addition to tramadol whereas in 'PO' group, nine patients received inj. diclofenac and one patient received diclofenac as well as PCM in addition to tramadol in the postoperative period, Figure 1a $\& 1$ b. The total tramadol as well as total analgesic requirement in 24 hours was found to be lower in PO group; however, the difference was statistically not significant. Figure 2 shows, the postoperative VAS pain scores were also comparable in both the groups at various time points.
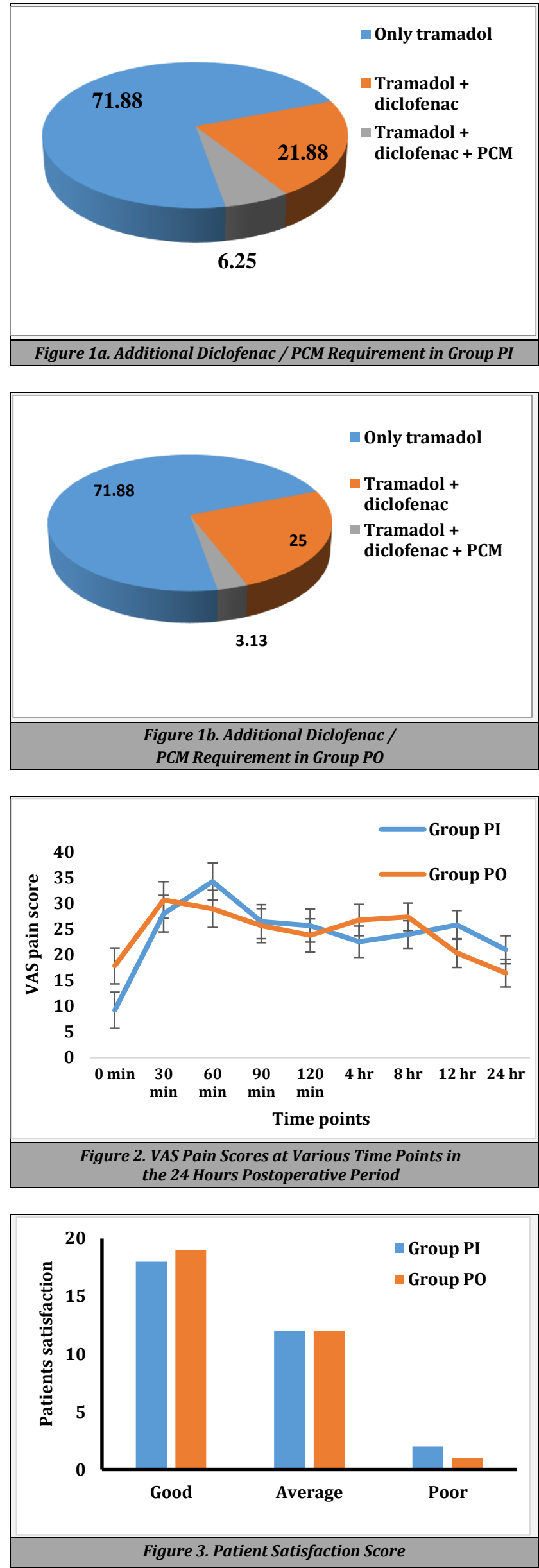
Two patients in group PI while four in PO group developed nausea and vomiting in the postoperative period after inj. tramadol, which was treated with inj. dexamethasone. The incidence of bradycardia, hypotension and postoperative nausea vomiting (PONV) were found to be similar between the groups. Also, the baseline, intraoperative and postoperative haemodynamic parameters were comparable in both the groups.

The patients' satisfaction with pain relief was graded as good / average / poor. In both PI and PO patient's satisfaction scores were comparable as shown in Figure 3.

\section{DISCUSSION}

The analysis of results across the groups in terms of time to first rescue analgesic, total analgesic requirements, VAS pain scores and patients' satisfaction does not show statistically significant difference with oral and i.v. paracetamol for the relief of pain in patients undergoing total abdominal hysterectomy. Many earlier studies have compared efficacy of oral and I.V. PCM during different types of surgical procedures; however, ours is the first study comparing these two routes of PCM administration in females undergoing total abdominal hysterectomy.

Intravenous paracetamol is very commonly prescribed for peri-operative pain relief. It provides onset of pain relief within 5 to 10 minutes after administration due to high bioavailability. However, IV preparation is expensive and needs to be given as infusion. Oral PCM is very cheap and more convenient than intravenous medication. Its pre-operative administration has been found to be effective to provide postoperative analgesia. The time to achieve maximum concentration with oral PCM has been reported to be one hour. ${ }^{22}$ Therefore in the present study, it was decided to give oral PCM at least 45 min before and IV PCM after the induction of anaesthesia.

Westhuizen et al. found maximum median plasma concentration of $19 \mathrm{mg} / \mathrm{L}$ with IV PCM and $13 \mathrm{mg} / \mathrm{L}$ with oral PCM. ${ }^{23}$ Although plasma concentration was higher with IV preparation, the difference was less marked after 150 minutes. The systemic availability of IV dose is almost $100 \%$ compared to oral PCM which is quoted as $69-84 \%$. However, the area under the absorption / time curve in healthy subjects is equivalent to that with IV PCM. Similarly, Langford et al. in their study observed that the difference in peak plasma concentrations was not statistically significant after one hour with oral and intravenous paracetamol administration. ${ }^{19}$

Our study results are in concordance with the results of some earlier studies. Fenlon et al. compared oral and IV PCM for lower third molar extraction, they demonstrated that oral PCM given at least 45 minutes before surgery was not inferior to IV PCM for providing postoperative analgesia. ${ }^{24}$ Pettersson et al. compared the analgesic efficacy of oral and IV PCM in terms of its opioid-sparing effect in patients who had undergone coronary artery bypass surgery. ${ }^{25}$ The use of opioid was significantly lower in the patients receiving IV PCM than in the oral PCM group; however, no difference was observed in pain scores on VAS scale at any time. In another study, there was no evidence of differences in pain or opioid consumption after receiving oral or IV PCM in patients undergoing laparoscopic cholecystectomy. ${ }^{26}$ A systematic review and meta-analysis was conducted to compare the efficacy and safety of intravenous and oral acetaminophen as adjunct to multimodal analgesia regimens for pain control after total knee and hip arthroplasty. Authors observed that pain relief and opioid consumption was similar among both the groups and no increased risk of postoperative pulmonary complications were seen. However, the evidence quality for each outcome was moderate as only 2 randomised controlled trails (RCT's) were studied involving 120 participants in the experiment group and 116 participants in the control group. Therefore, higher quality of RCTs are required for further research. ${ }^{27}$

A recent systematic review by Mallama et al. suggested that route of paracetamol administration does not affect pain or any other postoperative outcomes. However, there was an insufficient evidence to exclude important clinical effects and overall, the quality of evidence was poor due to inadequate sample size. The studies included in this systematic review were carried out in hip and knee arthroplasties, laparoscopic cholecystectomy, hernia, varicose veins, ENT surgeries, dental surgery, coronary artery bypass, and Caesarean section. No study till now has involved patients undergoing hysterectomy. ${ }^{28}$

\section{CONCLUSIONS}

Efficacy of oral PCM $1 \mathrm{~g}$ administered about 45 min before induction is comparable to IV PCM $1 \mathrm{~g}$ infused after induction with respect to time to first rescue analgesic, postoperative pain scores, postoperative 24 hours analgesic requirements, patient satisfaction scores and side effects in patients undergoing total abdominal hysterectomy. Considering the similar efficacy and side effect profile, but at a much lower cost of oral PCM, routine administration of oral PCM 45 min before induction may be an acceptable alternative to routine intraoperative IV PCM infusion.

\section{Limitations of the Study}

It was decided to give oral PCM at least 45 min before and IV PCM after induction of anaesthesia. These timings of drug administration could not be accurately controlled. However, the difference in timings of drug administration was clinically as well as statistically insignificant.

Data sharing statement provided by the authors is available with the full text of this article at jemds.com.

Financial or other competing interests: None.

Disclosure forms provided by the authors are available with the full text of this article at jemds.com.

\section{REFERENCES}

[1] Moore RA, Derry S, Straube S, et al. Validating speed of onset as a key component of good analgesic response in acute pain. Eur J Pain 2015;19(2):187-92.

[2] Sharma CV, Mehta V. Paracetamol: mechanisms and updates. Continuing Education in Anaesthesia Critical Care and Pain 2014;14(4):153-8. 
[3] Mattia A, Coluzzi F. What anesthesiologists should know about paracetamol (acetaminophen). Minerva Anestesiol 2009;75(11):644-53.

[4] Jahr JS, Lee VK. Intravenous acetaminophen. Anesthesiol Clin 2010;28(4):619-45.

[5] Schug SA, Sidebotham DA, McGuinnety $M$, et al. Acetaminophen as an adjunct to morphine by patientcontrolled analgesia in the management of acute postoperative pain. Anesth Analg 1998;87(2):368-72.

[6] Apfelbaum JL, Ashburn MA, Connis RT, et al. Practice guidelines for acute pain management in the perioperative setting: an updated report by the American Society of Anesthesiologists task force on acute pain management. Anesthesiology 2012;116(2):248-73.

[7] Nishimoto RN. OFIRMEV: an old drug becomes new again. Anesth Prog 2014;61(3):99-102.

[8] Memis D, Inal MT, Kavalci G, et al. Intravenous paracetamol reduced the use of opioids, extubation time and opioid-related adverse effects after major surgery in intensive care unit. J Crit Care 2010;25(3):458-62.

[9] Oscier CD, Milner QJ. Peri-operative use of paracetamol. Anaesthesia 2009;64(1):65-72.

[10] Arici S, Gurbet A, Türker G, et al. Preemptive analgesic effects of intravenous paracetamol in total abdominal hysterectomy. Agri 2009;21(2):54-61.

[11] 0"Neal JB. The utility of intravenous acetaminophen in the perioperative period. Front Public Health 2013;1:25.

[12] Jebaraj B, Maitra S, Baidya DK, et al. Intravenous paracetamol reduces postoperative opioid consumption after orthopedic surgery: a systematic review of clinical trials. Pain Res Treat 2013;2013:402510.

[13] Hernández-Palazón J, Tortosa JA, Martínez-Lage JF, et al. Intravenous administration of propacetamol reduces morphine consumption after spinal fusion surgery. Anesth Analg 2001;92(6):1473-6.

[14] Pettersson PH, Owall A, Jakobsson J. Early bioavailability of paracetamol after oral or intravenous administration. Acta Anaesthesiol Scand 2004;48(7):867-87.

[15] Divoll M, Ameer B, Abernethy DR, et al. Age does not alter acetaminophen absorption. J Am Geriatr Soc 1982;30(4):240-4.

[16] Perrott DA, Piira T, Goodenough B, et al. Efficacy and safety of acetaminophen versus ibuprofen for treating children's pain or fever: a meta-analysis. Arch Pediatr Adolesc Med 2004;158(6):521-6.

[17] Toms L, McQuay HJ, Derry S, et al. Single dose oral paracetamol (acetaminophen) for postoperative pain in adults. Cochrane Database Syst Rev 2008;2008(4):CD004602.
[18] Langford RA, Hogg M, Bjorksten AR, et al. Comparative plasma and cerebrospinal fluid pharmacokinetics of paracetamol after intravenous and oral administration. Anesth Anal 2016;123(3):610-5.

[19] Nath R, Dutta S, Medom K, et al. Evaluation of the analgesic efficacy and safety of intravenous paracetamol in comparision to intravenous tramadol for postoperative analgeisa in patients undergoing lower abdominal surgery. J Evol Med Dent Sci 2015;4(4):505-13.

[20] Engindeniz Z, Demircan C, Karli N, et al. Intramuscular tramadol vs. diclofenac sodium for the treatment of acute migraine attacks in emergency department: a prospective, randomised, double-blind study. J Headache Pain 2005;6(3):143-8.

[21] Sivapurapu V, Vasudevan A, Gupta S, et al. Comparison of analgesic efficacy of transversus abdominis plane block with direct infiltration of local anesthetic into surgical incision in lower abdominal gynecological surgeries. J Anaesthesiol Clin Pharmacol 2013;29(1):71-5.

[22] Jibril F, Sharaby S, Mohamed M, et al. Intravenous versus oral acetaminophen for pain: systematic review of current evidence to support clinical decision-making. Can J Hosp Pharm 2015;68(3):238-47.

[23] Van der Westhuizen J, Kuo PY, Reed PW, et al. Randomised controlled trial comparing oral and intravenous paracetamol (acetaminophen) plasma levels when given as preoperative analgesia. Anaesth Intensive Care 2011;39(2):242-6.

[24] Fenlon S, Collyer J, Giles J, et al. Oral vs intravenous paracetamol for lower third molar extractions under general anaesthesia: is oral administration inferior? $\mathrm{Br} \mathrm{J}$ Anaesth 2013;110(3):432-7.

[25] Pettersson PH, Jakobsson J, Öwall A. Intravenous acetaminophen reduced the use of opioids compared with oral administration after coronary artery bypass grafting. J Cardio thorac Vasc Anesth 2005;19(3):306-9.

[26] Plunkett A, Haley C, McCoart, et al. A Preliminary examination of the comparative efficacy of intravenous vs oral acetaminophen in the treatment of perioperative pain. Pain Medicine 2017;18(12):2466-73.

[27] Sun L, Zhu X, Zou J, et al. Comparison of intravenous and oral acetaminophen for pain control after total knee and hip arthroplasty: a systematic review and meta-analysis. Medicine 2018;97(6):e9751.

[28] Mallamma M, Valencia A, Rijs K, et al. A systematic review and trial sequential analysis of intravenous vs. oral perioperative paracetamol. Anaesthesia 2020;76(2):270-6. 